\title{
GROWTH RATES OF THE MEDITERRANEAN GECKO, HEMIDACTYLUS TURCICUS, IN SOUTHWESTERN LOUISIANA
}

\author{
Mark A. Paulissen ${ }^{1}$, Harry A. Meyer ${ }^{2}$, and Tabatha S. Hibbs ${ }^{3}$
}

\begin{abstract}
Aвstract.-We captured and marked Mediterranean geckos, Hemidactylus turcicus, occupying a one-story building in southwestern Louisiana in 1999-2000 and 2002-2005 and calculated 2 estimates of growth rate: length growth rate (difference in snout-vent length [SVL] between captures divided by time between captures) and mass growth rate (difference in gecko mass between captures divided by time between captures). Both length growth rate and mass growth rate were significantly negatively correlated with gecko snout-vent length. When data from all years were combined, adult female geckos showed greater mean length growth rates and mean mass growth rates than males, but the trend was not statistically significant. Length growth rate and mass growth rate varied dramatically between years; neither correlated with yearly differences in rainfall. Comparison of our results to studies done in Texas and Florida showed that Mediterranean geckos in Louisiana had the lowest mean length growth rates and a much wider range of variation.
\end{abstract}

Resumen.-Capturamos y marcamos Gecos del Mediterráneo, Hemidactylus turcicus, que ocupaban un edificio de un piso en el suroeste de Louisiana en 1999 a 2000 y 2002 a 2005 y calculamos dos cálculos de tasas de crecimiento: La "Tasa de Crecimiento de Longitud" (la diferencia entre la longitud de hocico a cloaca entre capturas dividida por el periodo entre capturas) y la "Tasa de Crecimiento de Masa" (la diferencia entre la masa del geco entre capturas dividida por el periodo entre capturas). Las dos tasas tenían una correlación significantemente negativa con la longitud de hocico a cloaca del geco. Cuando combinamos los datos de todos los años, las hembras adultas de los gecos mostraron Tasas Medias de Crecimiento de Longitud y Tasas Medias de Crecimiento de Masa mayores que los machos, pero la tendencia no fue estadísticamente significativa. Las dos tasas variaron dramáticamente entre años; ninguna correlacionó fuertemente con las diferencias anuales en pluviosidad. Una comparación de nuestros resultados con estudios hechos en Texas y en Florida mostró que los gecos de Louisiana tenían Tasas Medias de Crecimiento de Longitud. Los gecos de Louisiana exhibieron una gama mucha más amplia de variación en Tasas de Crecimiento de Longitud.

The Mediterranean gecko, Hemidactylus turcicus, is a nonnative gekkonid lizard that was introduced into Florida in the early 20th century (Stejneger 1922). The species has subsequently expanded its range into the southern one-third of the United States from Florida to California (NatureServe, http: //www.nature serve.org/explorer), as well as having several populations and isolated sightings further north in Maryland (Norden and Norden 1991), Virginia (Kleopfer et al. 2006), and South Dakota (Platt et al. 2008). Its dispersal has been aided by unintentional and intentional transportation of eggs or live lizards by humans (Davis 1974, Locey and Stone 2006). The Mediterranean gecko is a small (adult snout-to-vent length [SVL] 42-55 mm) edificarian lizard that lives on and in buildings and other artificial structures. Mediterranean geckos prowl around on the outside walls of buildings at night to locate small arthropods, many of which are attracted to outside lighting (Saenz 1996, Punzo
2001). During the day, geckos hide behind building features, such as drain pipes or light fixtures, or in holes or cracks in building masonry (Rose and Barbour 1968, Williams and McBrayer 2007).

The Mediterranean gecko's expanding geographic distribution in the United States, its success at colonizing new areas, and its utility as a model for ecological dispersal have spurred many studies of Mediterranean gecko population biology. Some of these studies included a mark-recapture component that enabled researchers to identify movement patterns of geckos within and between the buildings they occupy (Selcer 1986, Klawinski 1991, Punzo 2001, Locey and Stone 2006, 2008, Stabler et al. 2012, Paulissen et al. 2013). However, only 2 of these studies measured geckos at every capture to permit estimation of gecko growth rates: Selcer (1986) studied a southern Texas population on the campus of UT-Pan American University in Edinburg, Texas, and Punzo

\footnotetext{
${ }^{1}$ Department of Natural Sciences, Northeastern State University, Tahlequah, OK 74464. E-mail: paulisse@nsuok.edu

${ }^{2}$ Department of Biological and Health Sciences, McNeese State University, Lake Charles, LA 70609.

${ }^{3}$ Division of Communication and Fine Arts, Connors State College, Warner, OK 74469.
} 
(2001) studied a western Florida population on the campus of the University of Tampa. Both studies reported no significant difference in growth rates between males and females, and both noted that growth rate slowed as geckos grew larger. However, these studies measured only changes in gecko length (measured as snout-to-vent length) and did not check for year-to-year differences in gecko growth rates. To our knowledge, there are no data on changes in Mediterranean gecko mass over time, nor are there any data that permit examination of the possibility that Mediterranean gecko growth rates may vary from year to year.

As part of a long-term study of Mediterranean gecko population biology (Hibbs et al. 2004, Paulissen et al. 2013), we captured and marked Mediterranean geckos that occupied a one-story building on the campus of McNeese State University in southwestern Louisiana in 1999-2000 and 2002-2005. This population lives considerably farther north and thus has a shorter activity season than the 2 populations studied by Selcer (1986) and Punzo (2001) and so might be expected to show lower, or at least different, growth rates. We measured SVL and mass of Mediterranean geckos at each capture to estimate growth rate as change in length as well as change in mass over time. Herein, we present these data (1) to determine whether male and female Mediterranean geckos have similar growth rates; (2) to determine whether Mediterranean gecko growth rates vary substantially from year to year; and (3) to compare our results to those of Selcer (1986) from southern Texas and Punzo (2001) from western Florida to see what differences in Mediterranean gecko growth rates exist.

\section{Methods}

This study was conducted on the campus of McNeese State University, located in Lake Charles, Louisiana, $42 \mathrm{~km}$ north of the Gulf of Mexico and $35 \mathrm{~km}$ east of the Louisiana-Texas border. Mediterranean geckos were collected on the outside surface of Smith Hall (also known as the Round Building) located on the western edge of the campus $\left(30.181137^{\circ},-93.218114^{\circ}\right)$. Smith Hall is a circular one-story brick building that is $4 \mathrm{~m}$ tall and $135 \mathrm{~m}$ in circumference. The outside of the building is light-colored brick interspersed with doorways and irregularly spaced ground-to-roof windows. Lights on the surface of the building and in the overhanging portico provide illumination at night. The lights attract insects and other arthropods, which the geckos consume.

Mediterranean geckos were collected during at least 7 nights from spring through fall 1999-2005 (except in 2000 when geckos were collected for 5 nights and in 2001 when geckos were not collected). Sampling nights were generally about one month apart, except during late summer and fall 2003 and 2004 when additional sampling nights were undertaken to try to capture and mark neonates (Appendix). Surveys began approximately 30 min after sunset and lasted 2-3 h. Air temperature was always at least $20{ }^{\circ} \mathrm{C}$ at the start of each night's survey.

Mediterranean geckos were captured by hand, and the SVL of each gecko was measured to the nearest millimeter by using a plastic ruler. The sex of each gecko over $42 \mathrm{~mm}$ SVL was determined by checking for the presence of pre-anal pores: present in males, absent in females. Geckos smaller than $42 \mathrm{~mm}$ SVL were considered to be juvenile (Punzo 2001). Each gecko was weighed to the nearest $0.1 \mathrm{~g}$ by placing it in a pre-weighed bag and using a Pesola spring balance. After processing, each gecko was permanently marked by clipping 1-3 toes in a unique pattern (never more than one toe per foot). Previous study has shown that Mediterranean geckos can have as many as 4 toes removed without suffering a decline in ability to cling to a vertical surface (Paulissen and Meyer 2000). Each gecko was released at the site where it was first located; because released geckos typically ran into retreats, they were not recaptured during the night's survey.

For the 3 years from which we have the most capture data $(2002,2003$, and 2004), we obtained rainfall data from the Port of Lake Charles located $3.6 \mathrm{~km}$ northwest of the McNeese campus. We present the rainfall data for the entire year, as well as for the months of March through October (the active season for Mediterranean geckos in southwestern Louisiana), to determine whether a relationship exists between rainfall and Mediterranean gecko growth rates (see discussion).

\section{Data Analysis}

We calculated 2 estimates of Mediterranean gecko growth rates. The length growth rate was 
estimated by subtracting the SVL of the gecko at first capture from the SVL of the gecko at second capture and dividing by the number of months between captures (calculated as the number of days between captures divided by 30). A number of Mediterranean geckos showed a negative length growth rate, indicating that these geckos declined in SVL between captures (almost always by 1-2 $\mathrm{mm}$ ). Negative length growth rates are not an unusual result in studies of lizard growth rates (Schoener and Schoener 1978, James 1991, Doughty and Shine 1998) and are typically attributed to measurement error. We follow the usual convention of including negative length growth rates in the data analysis because it is not possible to distinguish negative measurement errors from positive measurement errors of a similar magnitude (James 1991) and because it is possible that Mediterranean geckos may sometimes shrink between captures (see discussion).

The mass growth rate was estimated by subtracting the mass of the gecko at the first capture from the mass of the gecko at the second capture and dividing by the number of months between captures. Only recaptures made within a single calendar year were included so as to eliminate the effect of slowed growth rates during the period of winter inactivity. Geckos that autotomized their tails as a result of being handled by us were excluded from the analysis. Some geckos were caught more than twice within a year; in these cases, growth rates were calculated for only the first recapture interval to avoid pseudoreplication. Mean length growth rates and mass growth rates were calculated (1) for all geckos combined; (2) separately for adult males and adult females for the entire data set; and (3) separately for the 3 years for which we have at least 16 recaptures per year: 2002, 2003, and 2004. Statistical comparisons of male versus female length growth rates and mass growth rates were made using $t$ tests on the entire data set and then separately for 2002, 2003, and 2004. Statistical comparisons of growth rates among 2002, 2003, and 2004 were made using ANOVA. Pearson correlation coefficients $(r)$ were calculated to determine whether growth rates slowed as gecko SVL increased, as has been found in other studies (Selcer 1986, Punzo 2001). We also compared the mean and range of the length growth rate to those found by Selcer (1986) in southern Texas and Punzo (2001) in western Florida. All statistics were run using MYSTAT 12 for Windows (SYSTAT 2007).

\section{RESUlTs}

A total of 578 Mediterranean geckos (225 adult males, 226 adult females, 127 juveniles) were captured during this study. We have data on 131 recaptures made within a single calendar year, and 121 of these are of adults. Both length growth rate and mass growth rate were significantly negatively correlated with gecko SVL (length growth rate: $r=-0.435$, $P<0.001$; mass growth rate: $r=-0.328, P<$ 0.001 ), indicating that as geckos grew larger, their growth rates decreased. This relationship held both for adult males (length growth rate: $r=-0.390, P=0.006$; mass growth rate: $r=$ $-0.42, P=0.002)$ and for adult females (length growth rate: $r=-0.740, P<0.001$; mass growth rate: $r=-0.396, P=0.006$ ). There were too few recaptures of juveniles to reliably analyze them separately.

\section{Sexual and Temporal Differences in \\ Mediterranean Gecko Growth Rates}

Analysis of data collected over the duration of the entire study (1999-2000, 2002-2005) showed that the mean length growth rate of adult females was nearly 3 times the mean length growth rate of adult males, though this difference was marginally nonsignificant (Table 1). The mean mass growth rate of adult females was also nearly 3 times the mean mass growth rate of adult males, though the difference was not statistically significant (Table 1). Analysis of data from 2002 to 2004 showed that both length growth rate and mass growth rate differed dramatically from year to year, though the differences failed to reach statistical significance for any group of gecko (Table 2). Considering all geckos together, mean length growth rate was greatest in 2002 and lowest in 2003 (Table 2). This trend was followed by adult males (which actually showed a small mean decline in length growth rate in 2003), as well as by adult females (Table 2). However, there were no statistically significant differences in mean length growth rate between males and females for any of the 3 years analyzed (2002: $t=-0.007, \mathrm{df}=12, P=$ 0.99; 2003: $t=1.38$, df $=45, P=0.16 ; 2004$ : 
TABLE 1. Means, standard deviations, and ranges of length growth rate and mass growth rate of adult male and adult female Mediterranean Geckos on Smith Hall on the campus of McNeese State University in Lake Charles, Louisiana, for all years combined (1999-2000, 2002-2005). The $P$ value of the $t$ test comparing the means of adult males to adult females is given; $n$ is the sample size. The limited data for juveniles are shown in Table 2 ; the maximum value for mass growth rate was from a juvenile.

\begin{tabular}{|c|c|c|c|}
\hline & Males $(n=62)$ & Females $(n=59)$ & $P$ \\
\hline \multicolumn{4}{|c|}{ Length growth rate $\left(\mathrm{mm} \cdot \mathrm{month}^{-1}\right)$} \\
\hline Mean & 0.52 & 1.40 & 0.109 \\
\hline SD & 2.71 & 3.22 & \\
\hline Range & -6.4 to 12.8 & -4.3 to 14.1 & \\
\hline \multicolumn{4}{|c|}{ Mass growth rate $\left(\mathrm{g} \cdot\right.$ month $\left.^{-1}\right)$} \\
\hline Mean & 0.051 & 0.144 & 0.317 \\
\hline SD & 0.297 & 0.662 & \\
\hline Range & -0.86 to 1.03 & -2.14 to 1.71 & \\
\hline
\end{tabular}

TABLE 2. Means of length growth rate and mass growth rate of Mediterranean Geckos on Smith Hall on the campus of McNeese State University in Lake Charles, Louisiana, for the years 2002-2004. Standard deviations are given in parentheses and $n$ is the sample size. The $P$ values for ANOVAs comparing the means among the 3 years are given; note there are no significant differences among years for either growth rate for any sex/age category. A series of $t$ tests comparing adult males to adult females within each year showed no significant difference between the sexes for any year for either length growth rate or mass growth rate (all $P$ values $>0.05$ : see results).

\begin{tabular}{|c|c|c|c|c|}
\hline & 2002 & 2003 & 2004 & $P$ \\
\hline \multicolumn{5}{|c|}{ Length growth rate $\left(\mathrm{mm} \cdot \mathrm{month}^{-1}\right)$} \\
\hline All geckos & $\begin{array}{c}2.10(4.19) \\
\quad n=16\end{array}$ & $\begin{array}{c}0.34(2.62) \\
n=49\end{array}$ & $\begin{array}{c}1.16(2.78) \\
n=44\end{array}$ & 0.10 \\
\hline Adult males & $\begin{array}{c}1.94(4.19) \\
n=8\end{array}$ & $\begin{array}{c}-0.03(2.03) \\
n=26\end{array}$ & $\begin{array}{c}0.74(3.23) \\
\quad n=17\end{array}$ & 0.23 \\
\hline Adult females & $\begin{array}{c}1.92(5.13) \\
\quad n=6\end{array}$ & $\begin{array}{c}0.99(2.84) \\
n=21\end{array}$ & $\begin{array}{c}1.35(2.41) \\
n=21\end{array}$ & 0.79 \\
\hline Juveniles & $\begin{array}{c}3.31(2.25) \\
n=2\end{array}$ & $\begin{array}{c}-1.74(6.57) \\
n=2\end{array}$ & $\begin{array}{c}1.64(2.98) \\
n=6\end{array}$ & 0.40 \\
\hline \multicolumn{5}{|c|}{ Mass growth rate $\left(\mathrm{g} \cdot\right.$ month $\left.^{-1}\right)$} \\
\hline All geckos & $\begin{array}{c}0.271(0.524) \\
n=16\end{array}$ & $\begin{array}{c}0.105(0.475) \\
n=49\end{array}$ & $\begin{array}{c}0.052(0.577) \\
n=44\end{array}$ & 0.37 \\
\hline Adult males & $\begin{array}{c}0.194(0.386) \\
n=8\end{array}$ & $\begin{array}{c}0.041(0.309) \\
n=26\end{array}$ & $\begin{array}{c}-0.075(0.274) \\
n=17\end{array}$ & 0.13 \\
\hline Adult females & $\begin{array}{c}0.362(0.770) \\
n=6\end{array}$ & $\begin{array}{c}0.180(0.635) \\
n=21\end{array}$ & $\begin{array}{c}0.044(0.522) \\
n=21\end{array}$ & 0.50 \\
\hline Juveniles & $\begin{array}{c}0.306(0.173) \\
n=2\end{array}$ & $\begin{array}{c}0.143(0.404) \\
n=2\end{array}$ & $\begin{array}{c}0.443(0.138) \\
n=6\end{array}$ & 0.93 \\
\hline
\end{tabular}

TABLE 3. Comparison of length growth rate of Mediterranean Geckos from 3 populations reported by 3 different studies. Data are for both sexes and all size classes combined. All measurements are in millimeters per month; $n$ is the sample size.

\begin{tabular}{|c|c|c|c|}
\hline & $\begin{array}{c}\text { Texas } \\
\text { (Selcer 1986) } \\
n=93\end{array}$ & $\begin{array}{c}\text { Florida } \\
(\text { Punzo 2001) } \\
n=57\end{array}$ & $\begin{array}{c}\text { Louisiana } \\
\text { (this study) } \\
n=131\end{array}$ \\
\hline Mean length growth rate $\left(\mathrm{mm} \cdot \mathrm{month}^{-1}\right)$ & 1.49 & 2.03 & 0.94 \\
\hline $95 \%$ Confidence limits & $-0.27,3.25$ & $1.91,2.15$ & $0.41,1.46$ \\
\hline Minimum length growth rate & 0.0 & 0.8 & -6.4 \\
\hline Maximum length growth rate & 10.9 & 6.9 & 14.1 \\
\hline
\end{tabular}

$t=0.64, \mathrm{df}=36, P=0.51)$. Mean mass growth rate of all geckos combined was highest in 2002 and lowest in 2004 (Table 2). Adult males showed their greatest mean mass growth rate in 2002, had a lower mean mass growth rate in
2003, and had a negative mean mass growth rate in 2004. Adult females showed the same pattern of changes in mean mass growth rates, although their mean mass growth rate remained positive in all 3 years (Table 2). As with the 
length growth rates, there were no significant differences between mean mass growth rate of males and females for any of the 3 years analyzed (2002: $t=0.54$, df $=12, P=0.60 ; 2003$ : $t=1.92, \mathrm{df}=45, P=0.33 ; 2004: t=0.90, \mathrm{df}$ $=36, P=0.40$ ).

\section{Comparison to Other Mediterranean Gecko Populations}

The mean length growth rate of our population of Mediterranean geckos from southwestern Louisiana was substantially lower than that of populations from southern Texas (Selcer 1986) and western Florida (Punzo 2001; Table 3). The range of length growth rates was considerably greater in our Louisiana population, extending from a minimum of $-6.4 \mathrm{~mm}$. month $^{-1}$ to a maximum of $14.1 \mathrm{~mm} \cdot$ month $^{-1}$. The lowest length growth rate reported by Selcer (1986) was $0.0 \mathrm{~mm} \cdot \mathrm{month}^{-1}$, and the lowest reported by Punzo (2001) was $0.8 \mathrm{~mm}$. month $^{-1}$; that is, neither study recorded a decline in gecko SVL between recaptures. In contrast, 34 of the Louisiana geckos (26\% of our sample) showed a negative length growth rate in our study. The maximum length growth rate we recorded was from a young female that we originally caught 14 June 2005 at an SVL of $32 \mathrm{~mm}$. When recaptured 4 August 2005 , the female measured at an SVL of 55 $\mathrm{mm}$. This gecko was one of 5 (2 male, 3 female) that showed a length growth rate greater than the maximum reported by either Selcer (1986) or Punzo (2001).

\section{Discussion}

An intriguing result of this study was that male and female Mediterranean geckos showed different patterns of growth rates. Females showed mean length growth rates and mean mass growth rates nearly 3 times those of males when data from all years of the study were combined (though the differences were not statistically significant; Table 1). Females showed positive mean length growth rates and positive mean mass growth rates for all 3 years for which we have the most data (2002-2004), whereas males showed a negative mean growth rate for one of the 3 years (2003 for mean length growth rate, 2004 for mean mass growth rate, Table 2). Furthermore, the mean mass growth rates of males were lower than those of females for all 3 years for which we have the most data (Table 2), though none of the differences was statistically significant. Certainly some of the differences in mass growth rates between males and females are attributable to reproductive status. During the breeding season, reproductively active females may not increase in mass due to "growth," but rather due to egg production. Furthermore, in a study of seasonal changes in fatbody mass, Selcer (1987) found that male Mediterranean geckos had the smallest fatbodies during the breeding season, a result he hypothesized may be due to decline in foraging opportunities because of frequent social interactions (such as conflicts with other males). Similar reasoning may also account for why male Mediterranean geckos lost mass on average during one of the 3 years of the study (2004), whereas female Mediterranean geckos gained mass on average in all 3 years. Analysis of sex differences in foraging success during and outside the breeding season is needed to test this hypothesis.

Mediterranean gecko growth rates vary widely from year to year. Adult males were particularly variable, showing high and positive mean length growth rates and mass growth rates in 2002 but low or even negative mean length and mass growth rates in other years (Table 2). The most obvious hypothesis to explain the yearly fluctuation in gecko growth rates is changing food availability. Unfortunately, we did not measure arthropod density on Smith Hall during most of the years of this study, so we have no data to directly test this hypothesis. Studies of growth rates of lizards inhabiting desert environments have often shown a tight correlation between rainfall and lizard growth rate mediated by increased food availability in wetter years (Dunham 1978, Krekorian 1984, Miranda and Andrade 2003). To determine whether a similar relationship existed for our population of Mediterranean geckos, we compared rainfall data taken from a weather station near our study site to growth rates for the years 2002-2004. As shown in Fig. 1, 2002 and 2004 were slightly wetterthan-normal years, whereas 2003 was a dry year. Both male and female Mediterranean geckos in our population showed their lowest mean length growth rates in the driest year of the study (for males, the mean length growth rate was actually negative in 2003; Table 2). However, the pattern of year-to-year changes in mean mass growth rates does not track well 


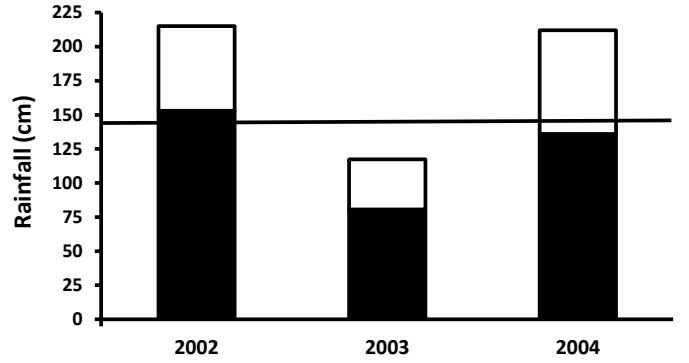

Fig. 1. Rainfall at the Port of Lake Charles, Louisiana (3.6 $\mathrm{km}$ from the campus of McNeese State University). Solid bars represent total rainfall during the main part of the Mediterranean gecko activity season (March-October); open bars represent total rainfall for the year. The annual average rainfall in Lake Charles, approximately $145 \mathrm{~cm}$ per year, is shown by the horizontal line.

with year-to-year changes in rainfall for either males or females. This poor tracking suggests a lack of correlation between rainfall and Mediterranean gecko growth rates for our population. Perhaps the annual differences in rainfall during our study were not sufficient to produce dramatic changes in prey availability in the mesic urban environment of southwestern Louisiana the way they do in desert environments. Alternatively, perhaps the artificial nature of the Mediterranean gecko environment, in particular the steady supply of arthropods attracted by outside lights to buildings occupied by geckos, blunts the effect that rainfall may actually have on arthropod availability (compared to desert habitats where the supply of arthropod prey is not as large or as dependable).

The 2 previous studies of Mediterranean gecko length growth rates, Selcer (1986) and Punzo (2001), reported an inverse correlation between SVL and length growth rate. This inverse correlation was also found in our study, suggesting that declining length growth rates with increased individual size is the norm in this species. The mean length growth rate we found for Mediterranean geckos in southwestern Louisiana was considerably lower than the mean length growth rates found by Selcer (1986) in Texas or by Punzo (2001) in Florida (Table 3). Spatial variation in Mediterranean gecko growth rates is not surprising; an earlier study conducted on the campus of McNeese State University found statistically significant differences in mean mass growth rates of geckos from 2 buildings $<300 \mathrm{~m}$ apart (Hibbs et al. 2004). That difference was attributed to dramatic differences in arthropod abundance between the 2 buildings; perhaps there were also differences in food abundance among the Louisiana, Texas, and Florida sites. Alternatively, there may be a climatological reason for the difference; the Louisiana population we studied lies further north than either the southern Texas population studied by Selcer (1986) or the western Florida population studied by Punzo (2001). Certainly the temperature regimes are different, and the number of days warm enough for Mediterranean gecko activity is probably lower in Louisiana. What effect temperature and other climatological variables have on Mediterranean gecko growth rates is unknown.

The studies by Selcer (1986) and Punzo (2001) reported no cases of Mediterranean geckos shrinking in length between recaptures. However, $26 \%$ of the Louisiana geckos we studied showed a negative length growth rate, indicating a decline in SVL from one capture to the next. Declines in length between captures have been found in several studies of lizard growth rates (Schoener and Schoener 1978, James 1991, Doughty and Shine 1998) and have been attributed to measurement error. Though error may account for some of our results (in particular when a small loss in length translated into a large negative growth rate because of the short time interval between captures), it is likely that many of our Mediterranean geckos did in fact shrink between captures. Most of the adult Mediterranean geckos that showed a negative length growth rate were males, yet there is no reason to believe that we made more measurement errors on males than on females. Also, $81 \%$ of the records of males showing negative length growth rates occurred in 2003 and 2004, the same 2 years for which males showed their lowest mean mass growth rates (Table 2). This result suggests that in years during which male Mediterranean geckos gain little or actually lose mass on average, they were more likely to lose length as well, a result that is unlikely to occur from measurement errors alone. Decreases in length have been documented for at least one other species of lizard, the Galapagos marine iguana, which was shown to shrink in length during years of low food availability (Wikelski and Thom 2000). Though the biology of marine iguanas and 
Mediterranean geckos is certainly different, the possibility that geckos (and by extension other lizards) may occasionally lose length between recaptures should not be discounted.

\section{ACKNOWLEDGMENTS}

We thank the following individuals for help with this study: M. Bret, J. Vienneau, and S. Reymann. We also wish to thank the McNeese State University Police Department for their cooperation during our nocturnal gecko collection activities. This study was approved by the McNeese State University Institutional Animal Care and Use Committee (protocol \#1-98). Geckos were collected under the authority of permits granted to M. Paulissen by the Louisiana Department of Wildlife and Fisheries (LNHP-99-019, LNHP-00-002, LNHP-02-018, LNHP-03-019, LNHP-04-020, LNHP-05-004). Spanish translation of the abstract was done by Beth Green-Nagle and Alejandra Mera.

\section{Literature Cited}

DAVIS, W.K. 1974. The Mediterranean gecko in Texas. Journal of Herpetology 8:77-80.

Doughty, P., AND R. SHINE. 1998. Reproductive energy allocation and long-term energy stores in a viviparous lizard (Eulamprus tympanum). Ecology 79: 1073-1083.

Dunham, A.E. 1978. Food availability as a proximate factor influencing individual growth rates in the iguanid lizard Sceloporus merriami. Ecology 59:770-778.

Hibbs, T.S., M.A. Paulissen, and H.A. Meyer. 2004. Spatial variation in populations of the Mediterranean gecko on a Louisiana college campus. Proceedings of the Louisiana Academy of Sciences 67:10-16.

James, C.D. 1991. Growth rates and ages at maturity of sympatric scincid lizards (Ctenotus) in central Australia. Journal of Herpetology 25:284-295.

KLAWINSKI, P.D. 1991. Home range, activity, and spatial distribution of the Mediterranean gecko Hemidactylus turcicus. Master's thesis, Stephen F. Austin State University, Nacogdoches, TX.

Kleopfer, J., S. Watson, and J. Mitchell. 2006. Geographic distribution: Hemidactylus turcicus. SSAR Herpetological Review 37:106-107.

Krekorian, C.O. 1984. Life history of the desert iguana, Dipsosaurus dorsalis. Herpetologica 40:415-424.

Locey, K.J., AND P.A. STONE. 2006. Factors affecting range expansion in the introduced Mediterranean gecko, Hemidactylus turcicus. Journal of Herpetology 40: $526-530$.

. 2008. Ontogenetic factors affecting diffusion dispersal in the introduced Mediterranean gecko,
Hemidactylus turcicus. Journal of Herpetology 42: 593-599.

Miranda, J.P., AND G.V. ANDrade. 2003. Seasonality, diet, perch use, and reproduction of the gecko Gonatodes humeralis from eastern Brazilian Amazon. Journal of Herpetology 37:433-438.

Norden, A.W., And B.B. Norden. 1991. The Mediterranean gecko (Hemidactylus turcicus) in Baltimore, Maryland. Maryland Naturalist 33:57-58.

Paulissen, M.A., And H.A. Meyer. 2000. The effect of toe-clipping on the edificarian gecko Hemidactylus turcicus (Lacertilia: Gekkonidae). Journal of Herpetology 34:282-285.

Paulissen, M.A., H.A. Meyer, and T.S. Hibbs. 2013. Movement patterns and sociality of the Mediterranean gecko, Hemidactylus turcicus, in southwestern Louisiana. Southwestern Naturalist 58:344-350.

Platt, S.G., T.R. Rainwater, and S. Miller. 2008. Geographic distribution: Hemidactylus turcicus. SSAR Herpetological Review 39:238.

Punzo, F. 2001. The Mediterranean gecko, Hemidactylus turcicus: life in an urban landscape. Florida Scientist 64:56-66.

Rose, F.L., AND C.D. Barbour. 1968. Ecology and reproductive cycles of the introduced gecko, Hemidactylus turcicus, in the southern United States. American Midland Naturalist 79:159-168.

SAENZ, D. 1996. Dietary overview of Hemidactylus turcicus with possible implications of food partitioning. Journal of Herpetology 30:461-466.

Schoener, T.W., AND A.W. Schoener. 1978. Estimating and interpreting body-size growth in some Anolis lizards. Copeia 1978:390-405.

SELCER, K.W. 1986. Life history of a successful colonizer: the Mediterranean gecko, Hemidactylus turcicus, in southern Texas. Copeia 1986:956-962.

1987. Seasonal variation in fatbody and liver mass of the introduced Mediterranean gecko, Hemidactylus turcicus, in Texas. Journal of Herpetology 21: $74-78$.

Stabler, L.B., W.L. Johnson, K.J. Locey, and P.A. STONE. 2012. A comparison of Mediterranean gecko (Hemidactylus turcicus) populations in two temperate zone urban habitats. Urban Ecosystems 15: $653-666$.

Stejneger, L. 1922. Two geckos new to the fauna of the United States. Copeia 1922:56.

SYSTAT. 2007. MYSTAT Version 12 for Windows. SYSTAT Software Inc., Chicago, IL.

WiKelsKi, M., AND C. THOM. 2000. Marine iguanas shrink to survive El Niño. Nature 403:37-38.

Williams, S.C., AND L.D. MCBRaYER. 2007. Selection of microhabitat by the introduced Mediterranean gecko, Hemidactylus turcicus: influence of ambient light and distance to refuge. Southwestern Naturalist 52: 578-585.

Received 21 May 2013

Accepted 11 October 2013 
APPENDIX. Collection dates for each year of the study.

\begin{tabular}{ll}
\hline Year & Collection dates \\
\hline 1999 & 1 April, 1 May, 7 June, 1 July, 2 August, 4 September, 1 November \\
2000 & 16 February, 4 March, 31 May, 28 August, 6 September \\
2001 & None \\
2002 & 5 May, 2 June, 2 July, 7 August, 29 August, 12 September, 14 October \\
2003 & 26 April, 6 June, 8 July, 17 July, 15 August, 24 August, 2 September, 15 September, 14 October \\
2004 & 21 April, 27 May, 15 June, 19 July, 16 August, 26 August, 8 September, 15 September, 22 September, \\
2005 & 30 September \\
\hline
\end{tabular}

